\title{
Use of a Public Fishing Area Determined by Vehicle Counters with Verification by Trail Cameras
}

\author{
Greg Simpson \\ South Dakota Game, Fish and Parks, 4130 Adventure Trail, Rapid City, SD, USA \\ Email: greg.simpson@state.sd.us
}

How to cite this paper: Simpson, G (2018) Use of a Public Fishing Area Determined by Vehicle Counters with Verification by Trail Cameras. Natural Resources, 9, 188-197.

https://doi.org/10.4236/nr.2018.95012

Received: November 1, 2017

Accepted: May 25, 2018

Published: May 28, 2018

Copyright $\odot 2018$ by author and Scientific Research Publishing Inc. This work is licensed under the Creative Commons Attribution International License (CC BY 4.0).

http://creativecommons.org/licenses/by/4.0/

\section{c) (i) Open Access}

\begin{abstract}
This study was performed in order to determine visitation at remote areas that would be unaffordable due to logistic reasons. Four Trafx ${ }^{\mathrm{TM}}$ vehicle counters, each programmed with different settings, were placed along the lone access road to remotely sense the daily use activities and count accuracy at the New Underwood Lake Public Water Access Area. Use was corroborated during daylight hours with game cameras. Data was stratified between weekdays/weekends due to differences between the two periods. Two counter settings, threshold and delay, were best when set at a value of 8 , but a value of 16 for delay provided almost equal results. Overall, there were 38 counts of use per day for a total of 2318 over the 61 day period. This study demonstrated how vehicle counters, in combination with game cameras for verification, can aid managers for determining use in remote access areas. Future work may lead to identifying details for producing a surrogate to traditional angler use surveys.
\end{abstract}

\section{Keywords}

Public Areas, Visitation, Use Survey, Trafx Counters, Trail Camera

\section{Introduction}

Sport fisheries are a major component to inland fisheries in northern industrialized countries [1] [2] [3] [4]. From a perspective of the individual angler, sport fishing is defined as any method that is non-commercial in nature [3] [4]. Providing insight to the use of specific fisheries is long established techniques that have also seen modifications across time [5] [6] [7] [8]. These techniques, with expansions into other related fields (i.e. marketing outreach, management plans 
decision analysis and human dimensions) may increase the sustainability of inland fisheries [1].

Angler surveys in themselves can be divided into several categories [5]. Contacting anglers can occur through many methodologies with direct contact methods being commonly used. Roving creel and bus route are two designs commonly used in freshwater angler surveys, each with shortcomings; yet, having specific strengths in certain situations [5]. Roving site design methods are extensively used to sample recreational fisheries and provide information essential to management activities such as estimating fishing effort and catch rate and are used on a variety of waters [9]. Bus route designs have been shown to provide an excellent alternative to roving creel surveys, but are based on large water systems with many access sites being visited in a single day. Alternatively, mail surveys, including internet surveys, can obtain information for anglers past experiences and are at least perceived to have good accuracy and save money, yet have issues and biases as well [10] [11] [12] [13].

One concern to the proposals of Arlinghaus et al. [1] is the discordant between determining angler use in sparsely populated, rural areas and how to fiscally justify the collection when few contacts are anticipated. In some instances, a planned reduction of data gathering effort can achieve similar results [9]. Yet, it is prudent for researchers to determine if alternatives to data collection, different from the most common design approaches of creel surveys, can describe angler use in these situations. Estimating use by anglers is often necessary for managers to make informed decisions on fisheries management and can be used in prioritizing habitat and access improvements.

Use is commonly determined in situations where there is a need to quantify human activity in managed areas [14] [15]. To achieve this, a variety of methods for defining the processes of collecting data, and to determine the accuracy of the data collected have been developed by Watson et al. [14]. One of the approaches described by Watson et al. [14] demonstrated a theoretical method using mechanical counters paired with visual calibration. A recent work combined the use of traffic counters with visual observation to estimate daily and seasonal use [13]. Often human observers are used in the calibration method; however, this study considered if trail cameras could be used in lieu of more expensive alternatives. Other researchers have utilized cameras to aid in determining angler effort or fishery closure compliance [13] [16] [17]. This study was unique in that it utilizes remote sensing equipment and methods developed for determining use in rural areas. Most previous studies have relied on people to calibrate the values obtained from vehicle counters [14] [15]. No previous works have discussed utilizing remote counters and determining accuracy of counter settings to obtain the most accurate results. The objectives of this study were to: 1) determine if remote sensing equipment can aid fisheries managers in determining use in low population areas and if there are specific settings within the programming of remote sensing equipment that demonstrated better accuracy than others and 
2) investigate the extent that game cameras could be used for validation of remotely sensed data.

\section{Sampling Methods}

\subsection{Study Area}

New Underwood Lake Public Water Access Area (NULPWAA) is a 62.3 ha pubic recreation area northwest of New Underwood, South Dakota (population, 674) (Figure 1). The most proximate population center is Rapid City (population, 70,812) which lies $37.7 \mathrm{~km}$ west from New Underwood. About one-half of NULPWAA consists of a small dam that is managed for a number of warmwater fish species (i.e. largemouth bass (Micropterus salmoides), channel catfish (Ictalurus punctatus), bluegill (Lepomis macrochirus). Gravel roads allow public access to the shoreline of NULPWAA and were central in the project design.

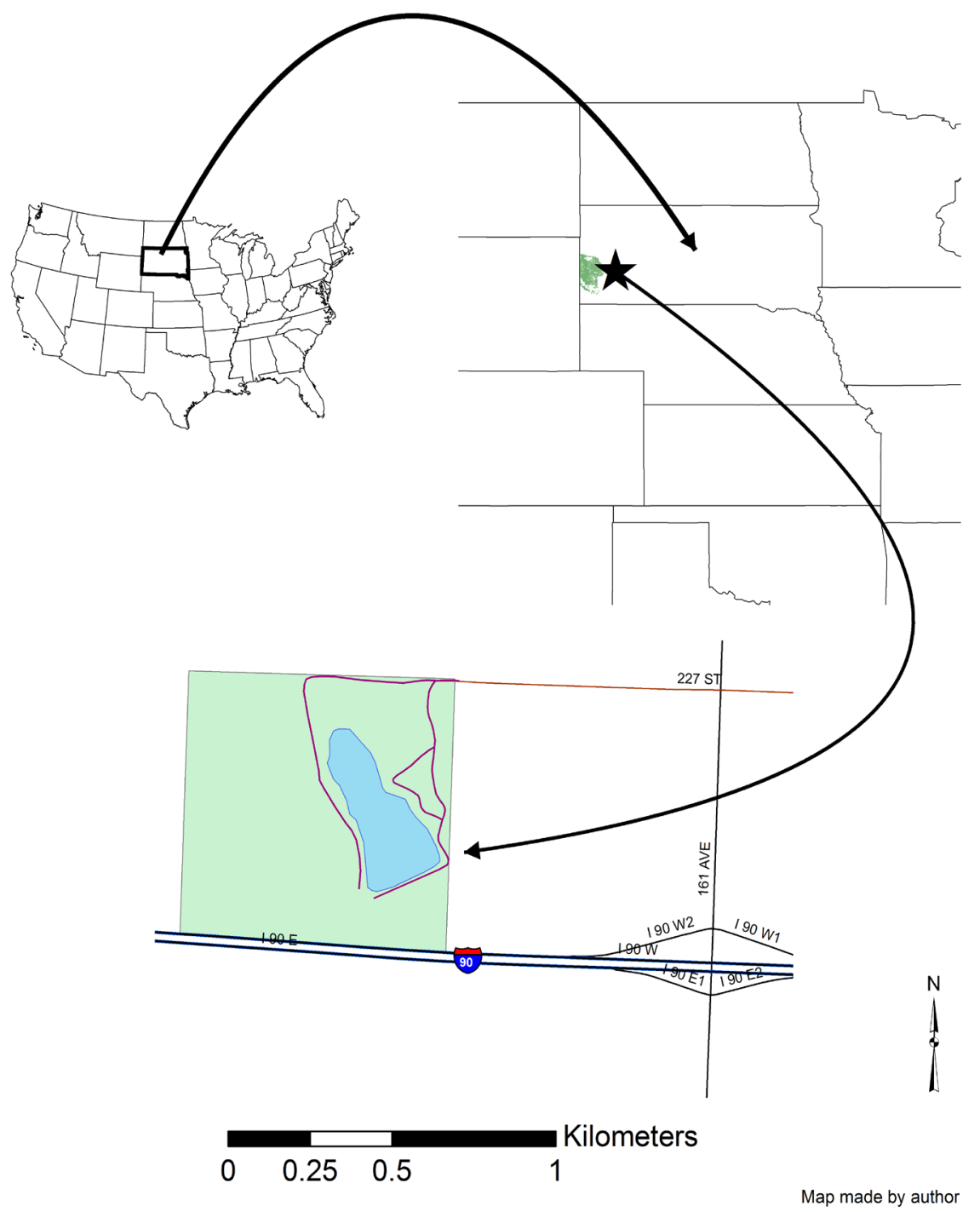

Figure 1. Location map of New Underwood Lake Public Water Access Area in relation to the northern plains states of the United States. 


\subsection{Vehicle Counter Settings}

Four Trafx ${ }^{\mathrm{TM}}$ vehicle counters (TRAFx Research Ltd., Canmore, Alberta, Generation 3)were placed just under the soil surface in separate watertight plastic boxes, 2.4 meters ( 8 feet) from the road edge where vehicles would be passing (Figure 2). These counters record a count with a change in the local electromagnetic field. Most combustion engines change the local electromagnetic field and thus would activate a count by the TRAFx counter. Each counter was programmed with differing variants of delay and threshold settings (Trafx Manual: Part II, Vehicle Counter G3, Jan 2010) (Table 1). Trafx ${ }^{\mathrm{TM}}$ counters have three settings (i.e. delay, threshold and rate) which can be adjusted to fit particular situations. The delay setting allows for a break between counts so that only one count is made per vehicle. Threshold adjusts for vehicle detection sensitivity. Delay and threshold were sequenced in order to determine accuracy. An assumption of the sampling design was that due to the gravel road, vehicle speed would be less than $50 \mathrm{~km} / \mathrm{hr}$ ( $30 \mathrm{mph}$ ) thus a rate setting of slow was used in this study. The Trafx ${ }^{\mathrm{TM}}$ counters used in this study sense a change in the magnetometer field through associated software for individual counts.

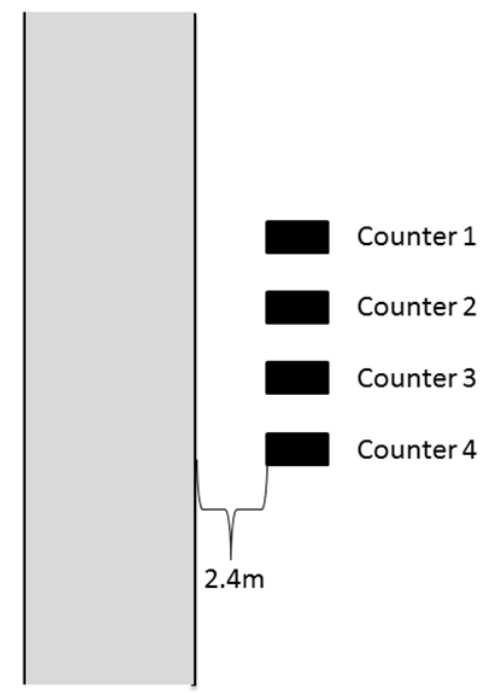

Figure 2. Representation of buried counters (not to scale) in relation to service road entrance to $\mathrm{New}$ Underwood Lake Public Water Access Area. The dark rectangles represent the counters contained within a plastic container and placed underground.

Table 1. Vehicle counter variants across four counters tested from May-August 2016.

\begin{tabular}{cccc}
\hline \multirow{2}{*}{$\begin{array}{c}\text { Specific } \\
\text { Counter }\end{array}$} & Counter Settings \\
\cline { 2 - 4 } & Delay & Threshold & Rate \\
\hline Counter 1 & 8 & 8 & Slow \\
Counter 2 & 8 & 3 & Slow \\
Counter 3 & 16 & 8 & Slow \\
Counter 4 & 16 & 3 & Slow \\
\hline
\end{tabular}




\subsection{Analysis of Counter Accuracy}

The months of June and July, 2016 were used in analysis of counter accuracy with each day considered as a separate sample. This gave a total sample size for counter accuracy of 61 (30 days in June, 31 days in July). Each day was run separately for accuracy through a process defined by Watson, et al. [14] for computation of an estimate of use. This process required the counts to be tested for accuracy and was accomplished in this study with the use of a trail camera system (Plotwatcher Pro ${ }^{\mathrm{TM}}$, http://day6outdoors.com/index.php/products/). The Plotwatcher system allows for photos to be taken at predetermined intervals (every five seconds in this study) and when finished the photos are "stitched" into one video file by each day via proprietary Tru-Video ${ }^{\mathrm{TM}}$ software (Day 6 Outdoors, LLC., Columbus, Georgia). Each video file was blind reviewed and later compared to the counter data. The paired data were used to establish a calibration relationship between the counter and observed analysis of accuracy, including a ratio estimator, for each counter setting was determined through the summation of each day period across the two month period.

\subsection{Overall Use}

Use at the NULPWAA was assumed to be related to angling during the sampling period. This assumption was based on that few other activities were legal (i.e. no hunting seasons) and much of the area roads are associated with lake use activities. Additionally, a separate, part-time creel survey was being conducted and reports of other nefarious activities were not reported. Data was stratified by the day of week to determine if there were significant differences of visitation between weekday and weekend/holiday periods through chi squared analysis. Counts were derived from the total number of Trafx data, corrected using the most accurate settings and corrected for day of the week bias as determined from data post-processing.

\section{Results}

\section{Comparison of Counter Settings}

From sixty-one sampling days, mechanical counts ranged from 37 to nearly 41 per day (Table 2). Strong correlations were observed between the average counts made by the counter and those verified by the camera system. An $r$ estimator [14] showed that the strongest relationship was obtained with counter 1 (delay 8 , threshold 8). This estimation indicated that 99 percent of the counts could be attributed to visitor traffic, with the remaining one percent due to other factors. The lowest relationship was indicated with counter 2 (delay 8, threshold 3) where 87 percent of the counts were verified between the systems as visitor use and 13 percent were from other causes. To account for any possible data bias based on day of the week, stratification based on day was investigated.

A chi-squared test of independence was performed to examine the relation between the days of the week and mechanical counts. The relation between these 
Table 2. Results of vehicle counts by mechanical versus photographic techniques with calculated "r estimation" for overall accuracy from May-August 2016.

\begin{tabular}{cccc}
\hline \multirow{2}{*}{$\begin{array}{c}\text { Counter } \\
\text { Number }\end{array}$} & \multicolumn{3}{c}{ Observation Method } \\
\cline { 2 - 4 } & Mean Mechanical $^{\mathrm{a}}$ & Mean Visual & R estimator \\
\hline Counter 1 & 37.05 & 37 & 0.993 \\
Counter 2 & 40.98 & 36 & 0.870 \\
Counter 3 & 36.13 & 35 & 0.980 \\
Counter 4 & 39.46 & 36 & 0.910 \\
\hline
\end{tabular}

${ }^{a} \mathrm{n}=61$ for all samples.

variables was significant $\left(\mathrm{x}^{2}=181.9, \mathrm{p}<0.05\right)$ and there were differences between visitation and days of the week. Due to this occurrence, the data was stratified by weekends and weekdays (Table 3). It was previously determined that counter one was the most accurate thus by using this counter alone we had on average 38 counts per day. Two counts, 50 and 51, were calculated from the weekend data from the various counter settings (Table 3). Results were similar for weekday counts as counts of 28 or 29 were calculated. The weekend and weekday calculated results produced an overall average estimate of 35 or 38 by the separate counters. These counts equal twice the number of vehicles using the NULPWAA as each vehicle would be counted going in and coming out.

\section{Discussion}

This study demonstrated that using counters to determine use in remote areas was a viable option. Here it was revealed that by testing four settings of threshold and delay using Trafx counters, a specific combination for threshold and delay was more accurate than others. Setting both the threshold and delay at a value of eight is the most accurate of the four settings tested. Others have noted that calibration of remote counters is imperative in the study design for accurate results [18] [19] [20] [21]. Watson et al. [14] do give a detailed review of alternatives for setting up studies, evaluation of counter data and thoughts on reduction of bias in the study design.

Interviewing every angler every time they fish is problematic and prohibitive based on monetary, spatial and temporal limitations [8] [9]. A statistical design must be employed to overcome this problem utilizing a subsample of the population based off a randomized schedule [5]. To produce statistically valid estimates of variables, such as catch and effort, all anglers must theoretically have the chance to be surveyed. Without a detailed knowledge of the angling group in remote areas, the possibility of interviewing all groups may not be met. Knowing the extent of visits to angling destinations can aid managers in the design phase of surveys. Potential impacts might include determining if stratification of the data between the weekdays and weekends for reduced bias [14] [21]. Malvestuto [22] and Pollock et al. [5] demonstrated how it was appropriate to stratify weekends and weekdays in some angler survey situations and Brandenburg and 
Table 3. Results of vehicle counts stratified by weekend/weekday from May-August, 2016 with corrected estimator from Watson et al. [10].

\begin{tabular}{lccc}
\hline & $\begin{array}{c}\text { Total Counts on } \\
\text { Weekend Days (N) with [CI }]\end{array}$ & $\begin{array}{c}\text { Total Counts on } \\
\text { Weekdays (N) } \\
\text { with [CI] }\end{array}$ & $\begin{array}{c}\text { Overall } \\
\text { Corrected } \\
\text { Estimator with } \\
{[\mathrm{CI}]}\end{array}$ \\
\hline Counter 1 & $51[1.7]$ & $29[0.9]$ & $38[1.1]$ \\
Counter 2 & $51[1.9]$ & $28[0.5]$ & $35[0.9]$ \\
Counter 3 & $50[1.8]$ & $29[0.5]$ & $35[1.6]$ \\
Counter 4 & $51[1.9]$ & $29[0.6]$ & $35[1.0]$ \\
\hline
\end{tabular}

Ploner [23] found differences between day types and user groups visiting a natural area. By acknowledging that, there are likely more anglers on weekends, and sampling these periods with a slightly greater effort produces results that are appropriate statistically. In many creel surveys, obtaining the needed number of interviews and associated catch data can be a limiting factor. Knowing that there are often a larger number of anglers recreating on weekends over the normal weekday period can often justify stratification of the sampling design towards a more heavily used period. Newman et al. [24] studied how stratified count designs compared with a total census and found that smaller sample sizes lead to large variance and poor confidence intervals for harvest rates.

Few studies derive fishing effort with the use of traffic counters. Douglas and Giles [19] did determine specific travel use in the planning of a creel survey. Lees + Associates [25] described the use of counters and placement at boat ramps and Ryan et al. [26] suggested that they used counters to generate estimates of angler effort, but did not report these findings. A more developed study presented how estimates of fishing effort and harvest could be improved, over common access point surveys, with supplemental data gathered by traffic counters [6]. Detailed studies relating the extent of angler effort through technology, such as trail counters, is still in its infancy. Other related fields have looked specific phenomena and were aided in data collection with traffic counters [27].

Trafx Counters ${ }^{\circledast}$ have been successfully used to study effects of roads and red squirrel movement patterns [27], and to determine the risk assessment for trees in an urban environment [28], but many efforts have been directed towards park and wilderness management and use. It has long been acknowledged that problems existed in data collection involving wilderness management [29]. In part, this was a stimulus for other projects [10] [15], where defined mechanisms and procedures were defined for future studies.

Use and the ability to utilize technology to determine a numerical estimate has increased over time. Issues in collecting user data were noted with possible "alternatives" towards the collection of data [29] [30]. Early work noted that many wilderness managers relied on best guesses for an estimate of use [31]. By utilizing advancements in technology, managers are now able to determine valuable information with lower costs than previous attempts. During this study, the use 
of remote counters in conjunction with verification through the use of trail camera systems was demonstrated to be a valuable tool in determining use at one lake. Verification by images was useful in that it indicated the data needed to be stratified by weekend and weekday for better accuracy. While some standard Angler Use metrics cannot be quantified using this method (e.g. catch, harvest numbers, etc.), it provides an inexpensive way for basic use estimates to be generated passively and shows promise for collecting use data at remote western fisheries. Using just a trail camera system as a measurement is one option for determining pressure at remote fishing areas. However, the time to review the images can be extensive and costly compared to vehicle counters alone.

\section{Acknowledgements}

The author would like to acknowledge the following individuals who assisted with the data collection, data entry, and editing this manuscript from the South Dakota Department of Game Fish and Parks: Joellyn Moine, Derek Hartl, Joe Mayrose and Michael E. Barnes.

\section{References}

[1] Arlinghaus, R., Mehner, T. and Cowx, I.G. (2002) Reconciling Traditional Inland Fisheries Management and Sustainability in Industrialized Countries, with Emphasis on Europe. Fish and fisheries, 3, 261-316. https://doi.org/10.1046/j.1467-2979.2002.00102.x

[2] Arlinghaus, R. (2006) Overcoming Human Obstacles to Conservation of Recreational Fishery Resources, with Emphasis on Europe. Environmental Conservation, 33, 46-59. https://doi.org/10.1017/S0376892906002700

[3] Arlinghaus, R. and Cooke, S.J. (2009) Recreational Fisheries: Socioeconomic Importance, Conservation Issues and Management Challenges. Recreational Hunting, Conservation and Rural Livelihoods: Science and Practice, 39-58. https://doi.org/10.1002/9781444303179.ch3

[4] Cowx, I.G., Arlinghaus, R. and Cooke, S.J. (2010) Harmonizing Recreational Fisheries and Conservation Objectives for Aquatic Biodiversity in Inland Waters. Journal of Fish Biology, 76, 2194-2215. https://doi.org/10.1111/j.1095-8649.2010.02686.x

[5] Pollock, K.H., Jones, C.M. and Brown, T.L. (1994) Angler Survey Methods and Their Application in Fisheries Management. American Fisheries Society Special Publication 25.

[6] Steffe, A.S., Murphy, J.J. and Reid, D.D. (2008) Supplemented Access Point Sampling Designs: A Cost-Effective Way of Improving the Accuracy and Precision of Fishing Effort and Harvest Estimates Derived from Recreational Fishing Surveys. North American Journal of Fisheries Management, 28, 1001-1008. https://doi.org/10.1577/M06-248.1

[7] Smallwood, C.B., Pollock, K.H., Wise, B.S., Hall, N.G. and Gaughan, D.J. (2012) Expanding Aerial-Roving Surveys to Include Counts of Shore-Based Recreational Fishers from Remotely Operated Cameras: Benefits, Limitations and Cost Effectiveness. North American Journal of Fisheries Management, 32, 1265-1276. https://doi.org/10.1080/02755947.2012.728181

[8] van Poorten, B. (2010) Effort Response of Urban Anglers to Varying Stocking Frequency and Density: Findings from the 2009 Fishing in the City Program and Pro- 
jections for Optimal Stocking. Report for the Freshwater Fisheries Society of British Columbia. Report, 9.

[9] Barnes, M.E., Simpson, G., Carreiro, J. and Voorhees, J. (2014) A Comparison of a Creel Census to Modeled Access-Point Creel Surveys on Two Small Lakes Managed as Put-and-Take Rainbow Trout Fisheries. Fisheries and Aquaculture Journal, 5, No. 1.

[10] Duda, M.D. and Nobile, J.L. (2010) The Fallacy of Online Surveys: No Data Are Better than Bad Data. Human Dimensions of Wildlife, 15, 55-64. https://doi.org/10.1080/10871200903244250

[11] Dillman, D.A. (2007) Mail and Internet Surveys: The Tailored Design Method. John Wiley and Sons, Inc., Hoboken, NJ.

[12] Gigliotti, L.M. (2011) Comparison of an Internet versus Mail Survey: A Case Study. Human Dimensions of Wildlife, 16, 1-8. https://doi.org/10.1080/10871209.2011.535241

[13] van Poorten, B.T. and Brydle, S. (2018). Estimating Fishing Effort from Remote Traffic Counters: Opportunities and Challenges. Fisheries Research, 204, 231-238. https://doi.org/10.1016/j.fishres.2018.02.024

[14] Watson, A.E., Cole, D.N., Turner, D.L. and Reynolds, P.S. (2000) Wilderness Recreation Use Estimation: A Handbook of Methods and Systems. Gen. Tech. Rep. RMRS-GTR-56. https://doi.org/10.2737/RMRS-GTR-56

[15] Cessford, G. and Muhar, A. (2003) Monitoring Options for Visitor Numbers in National Parks and Natural Areas. Journal Natural Conservation, 11, 240-250. https://doi.org/10.1078/1617-1381-00055

[16] Askey, P.J., Ward, H., Godin, T., Boucher, M. and Northrup, S. (2018) Angler Effort Estimates from Instantaneous Aerial Counts: Use of High-Frequency Time-Lapse Camera Data to Inform Model-Based Estimators. North American Journal of Fisheries Management, 38, 194-209. https://doi.org/10.1002/nafm.10010

[17] Lancaster, D., Dearden, P., Haggarty, D.R., Volpe, J.P. and Ban, N.C. (2017) Effectiveness of Shore-Based Remote Camera Monitoring for Quantifying Recreations Fisher Compliance in Marine Conservation Areas. Aquatic Conservation: Marine and Freshwater Ecosystems, 27, 804-813. https://doi.org/10.1002/aqc.2736

[18] Ross, J. (2005) Visitor Counters in Parks: Management Practice for Counter Calibration. Department of Conservation Technical Series 33, Department of Conservation, Wellington, $34 \mathrm{p}$.

[19] Douglas, J. and Giles, A. (2001) The Use of Traffic Counters to Plan Creel Surveys: A Case Study of Lake Dartmouth, Victoria, Australia. Fisheries Management and Ecology, 8, 543-546. https://doi.org/10.1046/j.1365-2400.2001.00254.x

[20] Cessford, G., Cockburn, S. and Douglas, M. (2002) Developing New Visitor Counters and Their Applications for Management. Monitoring and Management of Visitor Flows in Recreational and Protected Areas Conference, Vienna, 30 January-2 February 2002, 14-20.

[21] Ivy, M.I. (2002) Video Monitoring Visitors as a Management Tool: Identifying the Issues. Monitoring and Management of Visitor Flows in Recreational and Protected Areas Conference, Vienna, 30 January-2 February 2002, 483.

[22] Malvestuto, S.P. (1983) Sampling the Recreational Fishery. In: Nielsen, L.A. and Johnson, D.L., Eds., Fisheries Techniques, American Fisheries Society, Bethesda, 397-419.

[23] Brandenburg, C. and Ploner, A. (2002) Models to Predict Visitor Attendance Levels 
and the Presence of Specific User Groups. Monitoring and Management of Visitor Flows in Recreational and Protected Areas Conference, Vienna, 30 January-2 February 2002, 166-172.

[24] Newman, S.P., Rasmussen, P.W. and Andrews, L.M. (1997) Comparison of a Stratified, Instantaneous Count Creel Survey with a Complete Mandatory Creel Census on Escanaba Lake, Wisconsin. North American Journal of Fisheries Management, 17, 321-330. https://doi.org/10.1577/1548-8675(1997)017<0321:COASIC>2.3.CO;2

[25] Lees + Associates (2012) CLBMON-14 Boat Ramp Use Study (CLBMON 14, 2011 (Year 2) Progress Report. BC Hydro, Water License Requirements, Vancouver.

[26] Ryan, R.G., Gutknecht, E. and Megargle, D. (2007) Idaho Department of Fish and Game. Fishery Management Annual Report, November 2008, IDFG 08-114.

[27] Chen, H.L. and Koprowski, J.L. (2016) Barrier Effects of Roads on an Endangered Forest Obligate: Influences of Traffic, Road Edges and Gaps. Biological Conservation, 199, 33-40. https://doi.org/10.1016/j.biocon.2016.03.017

[28] Klein, R.W., Koeser, A.K., Hauer, R.J., Hansen, G. and Escobedo, F. (2016) Relationship between Perceived and Actual Occupancy Rates in Urban Settings. Urban Forestry and Urban Greening, 19, 194-201. https://doi.org/10.1016/j.ufug.2016.06.030

[29] Lucas, R.C. and Oltman, J.L. (1971) Survey Sampling Wilderness Visitors. Journal of Leisure Research, 3, 28-43. https://doi.org/10.1080/00222216.1971.11970013

[30] Hartill, B.W., Payne, G.W., Rush, N. and Bain, R. (2016) Bridging the Temporal Gap: Continuous and Cost-Effective Monitoring of Dynamic Recreational Fisheries by Web Cameras and Creel Surveys. Fisheries Research, 183, 488-497. https://doi.org/10.1016/j.fishres.2016.06.002

[31] McClaran, M. and Cole, N. (1993) Packstock in Wilderness: Use, Impacts, Monitoring and Management. USDA Forest Service, General Technical Report INT-301, Intermountain Research Station, Ogden. 